University of Wollongong

Research Online

Australian Institute for Innovative Materials -

Papers

Australian Institute for Innovative Materials

$1-1-2016$

\title{
Effective area and charge density of chondroitin sulphate doped PEDOT modified electrodes
}

Alexander R. Harris

University of Wollongong, alexh@uow.edu.au

Paul J. Molino

University of Wollongong, pmolino@uow.edu.au

Antonio G. Paolini

La Trobe University, a.paolini@latrobe.edu.au

Gordon G. Wallace

University of Wollongong, gwallace@uow.edu.au

Follow this and additional works at: https://ro.uow.edu.au/aiimpapers

Part of the Engineering Commons, and the Physical Sciences and Mathematics Commons

Research Online is the open access institutional repository for the University of Wollongong. For further information contact the UOW Library: research-pubs@uow.edu.au 


\title{
Effective area and charge density of chondroitin sulphate doped PEDOT modified electrodes
}

\begin{abstract}
Neural electrodes have been coated with electrodeposited poly-3,4-ethylenedioxythiophene doped with chondroitin sulphate. Optical and electrochemical methods were used to determine the effective electrode area, charge injection capacity and charge density of the modified electrodes. Deposition times of 15 to $60 \mathrm{~s}$ slightly increased the geometric and steady state diffusion electroactive areas while the linear diffusion electroactive area grew significantly, indicating an increase in electrode roughness. The effective electrode area and charge injection capacity were significantly smaller than PEDOT doped with previously tested dopants. In contrast to other dopant ions, the charge density determined from the geometric and steady state diffusion electroactive areas was nearly constant with increased deposition time while the linear diffusion charge density decreased.
\end{abstract}

\section{Keywords}

effective, density, charge, area, chondroitin, sulphate, doped, pedot, modified, electrodes

Disciplines

Engineering | Physical Sciences and Mathematics

\section{Publication Details}

Harris, A. R., Molino, P. J., Paolini, A. G. \& Wallace, G. G. (2016). Effective area and charge density of chondroitin sulphate doped PEDOT modified electrodes. Electrochimica Acta, 197 99-106. 
Effective Area and Charge Density of Dextran Sulphate Doped PEDOT Modified Electrodes

Alexander R. Harris ${ }^{1}$, Paul J. Molino ${ }^{2}$, Robert M.I. Kapsa ${ }^{2,3}$, Graeme M. Clark ${ }^{4}$, Antonio G. Paolini ${ }^{5}$, Gordon G. Wallace ${ }^{2}$

${ }^{1}$ HEARing CRC, Intelligent Polymer Research Institute, University of Wollongong, Wollongong, NSW, 2522, Australia

${ }^{2}$ Intelligent Polymer Research Institute, University of Wollongong, Wollongong, NSW, 2522, Australia

${ }^{3}$ Department of Neurosciences, St Vincents Hospital, Melbourne and Department of Medicine University of Melbourne, Fitzroy, Victoria, 3065, Australia

${ }^{4}$ School of Engineering, University of Melbourne, Parkville, Victoria, 3010, Australia

${ }^{5}$ Health Innovations Research Institute, College of Science, Engineering and Health, RMIT University, Bundoora, Victoria, 3083, Australia

Email: alexrharris@gmail.com 


\begin{abstract}
Neural electrodes suffer from poor chronic performance. Electrode modification is regularly used to improve device performance, biostability and biocompatibility. A large variety of doped conducting polymers have been proposed for optimising neural electrodes, but to date, none have achieved the required biostability and biocompatibility necessary for human application. Dextran sulfate is used as an antithrombotic and may be of use in improving neural electrode biocompatibility. Poly-3,4ethylenedioxythiophene was successfully doped with dextran sulfate (PEDOT-DS) by electropolymerisation on neural electrode arrays. Deposited films increased the electrode area and displayed a rough morphology. The electrode area and charge density were obtained using microscopy and reduction of $\mathrm{Ru}\left(\mathrm{NH}_{3}\right)_{6}{ }^{3+}$. Deposition charge, optical and linear electroactive areas were strongly correlated with deposition time. The optical charge density was greater on PEDOT-DS modified electrodes than unmodified and PEDOT-para-toluene sulfonate (PEDOT-pTs) modified electrodes. The linear charge density was smaller on PEDOT-DS modified electrodes than unmodified and PEDOT-pTs modified electrodes.
\end{abstract}

\title{
Keywords
}

Electroactive polymer; Deep Brain Stimulation; Neural prosthesis; Surface analysis; Charge Density 


\section{Introduction}

Implantable medical devices are increasingly being used for the treatment and control of disease. Many of these bionic implants incorporate electrodes for the recording and stimulation of excitable cells. A major limitation in the performance of these devices is fouling and encapsulation by proteins and scar tissue [1]. This encapsulation layer increases the distance between the electrode surface and the target tissue, reducing the sensitivity of the device [2]. Blocking of the electrode surface can also affect the electrical properties of the device and surrounding tissue [3].

Deposition of conducting polymers on electrode surfaces has been demonstrated by a number of research groups as a way of modifying electrode-tissue interfaces [4-6]. These conducting polymer modifications can alter the electrode roughness, hardness and surface functionality, and subsequently affect the immune response to the implanted device. Conducting polymers must be doped with a charged species to maintain charge neutrality, and a range of different dopant ions have been demonstrated [7]. Many of the original dopant ions were small species such as perchlorate or sulfate, or other polymers such as polystyrene sulfonate. More recently, a number of biologically relevant species have been used to dope conducting polymers [8-10]. Dextran sulfate is a polysaccharide that is regularly used as an antithrombotic. Its ability to act as a dopant in polypyrrole and maintain cultured cells has been demonstrated [8-10]. The incorporation of this type of biopolymer into an electrode for implantation into human or animal tissue may reduce the level of fouling and encapsulation leading to improved long term performance.

When determining the suitability of an electrode material for neural stimulation, the charge density is typically measured. The charge density defines the amount of charge an electrode can deliver per unit area. By increasing the charge density of an electrode, the size of the implant can be reduced, potentially allowing targeted stimulation of individual neurons and reducing the foreign body response to the implanted device. Platinum is used for most human bionic devices, and the charge density can be determined by hydride reduction and stripping in acidic solutions using cyclic voltammetry [11]. This mechanism is not suitable for most other electrode surfaces, and we recently proposed reduction of a solution soluble redox species, $\mathrm{Ru}\left(\mathrm{NH}_{3}\right)_{6}{ }^{3+}$, as an alternative [12]. Mass transport of the redox species to the electrode surface is affected by voltammetric scan rate, and subsequently, a linear and radial diffusion profile (at fast and slow scan rates respectively) results in two different charge density values; measurement of a geometric area provides a third charge density value. Comparison of each charge density value provides important information on the electrode morphology. By varying dopant ion, it then becomes possible to tailor the electrochemical, morphological and material properties of conducting polymer modified neural electrodes. 
Recently PEDOT-DS has been shown to exhibit good biocompatibility through the adhesion of extracellular matrix proteins and PC12 neuronal cells on unstimulated polymers (AMI paper). To gain a greater understanding of the potential benefits of incorporating dextran sulfate, this article measures the area and charge density of microelectrode arrays modified with electrodeposited poly-3,4ethylenedioxythiophene doped with dextran sulfate (PEDOT-DS). The results are compared to PEDOT doped with para-toluene sulfonate (pTs) which has been found to have a high charge density and good acute recording performance [13].

\section{Materials and Methods}

3,4-ethylenedioxythiophene (EDOT), dextran sulfate sodium salt (DS, average MW > 500,000), sodium para-toluene sulfonate ( $\left.\mathrm{Na}_{2} \mathrm{pTS}\right)$, hexaammineruthenium(III) chloride $\left(\mathrm{Ru}\left(\mathrm{NH}_{3}\right)_{6} \mathrm{Cl}_{3}\right)$ (SigmaAldrich) and $99.0 \%$ di-sodium phosphate (Fluka) were used as received. Polymer coatings were deposited on 4 shank, 32 electrode ( 8 electrodes per shank), $413 \mu \mathrm{m}^{2}$ nominal geometric area platinum electrodes with $200 \mu \mathrm{m}$ pitch (Neuronexus Technologies - A4x8-5mm-200-200-413). Conducting polymer coatings with different dopants were electrochemically deposited onto individual microelectrodes via a potentiostat (CH660D, CH Instruments) from mixed solutions containing $10 \mathrm{mM}$ EDOT and $0.1 \mathrm{M} \mathrm{Na}_{2} \mathrm{pTs}$ or $2 \mathrm{mg} \mathrm{mL}^{-1} \mathrm{DS}$ in deionised water. Potentiostatic growth was performed in a three-electrode configuration using one microelectrode as the working electrode, $\mathrm{Ag} / \mathrm{AgCl}(3 \mathrm{M}$ $\mathrm{NaCl}$ ) as reference electrode and $\mathrm{Pt}$ mesh as counter electrode. Solutions were degassed for 30 minutes with nitrogen before depositing the electrode coatings. All polymers were deposited at $1 \mathrm{~V} \mathrm{vs} \mathrm{Ag} / \mathrm{AgCl}$. PEDOT-DS was deposited for 4 different times $(15,30,45$ or $60 \mathrm{~s})$, PEDOT-pTs was deposited for 45s as recommended in our previous article [13]. 2 probes were coated with PEDOT-DS, 4 electrode sites coated at each deposition time in a staggered array as previously described [13], leaving 12 uncoated platinum electrodes and 4 PEDOT-pTS coated electrodes as controls.

Electrodes were imaged using a BX61 optical microscope (Olympus) and the area measured with ImageJ (figure 1). Electrochemical analysis was undertaken in $0.3 \mathrm{M}$ phosphate buffer in deionised water and the electroactive areas measured by addition of $5 \mathrm{mM} \mathrm{Ru}\left(\mathrm{NH}_{3}\right)_{6}{ }^{3+}$. Test solutions were not degassed to better represent conditions in vivo. A CHI660B potentiostat with CHI684 multiplexer (CH Instruments) were used to perform cyclic voltammetry at each of the individually addressable working electrode sites. A 3 electrode configuration was used with a $\mathrm{Ag} / \mathrm{AgCl}(3 \mathrm{M} \mathrm{KCl})$ reference and Pt mesh counter electrode. Charge density measurements were performed using cyclic voltammetry over a range of 0.8 to $-0.8 \mathrm{~V} \mathrm{vs} \mathrm{Ag} / \mathrm{AgCl}$ at a scan rate of $100 \mathrm{mV} \mathrm{s}^{-1}$. Electroactive area measurements were undertaken over a range of 0 to $-0.5 \mathrm{~V}$ varying the scan rate from $10 \mathrm{mV} \mathrm{s}^{-1}$ to $1 \mathrm{~V} \mathrm{~s}^{-1}$.

\section{Results}


The platinum electrodes were coated as described previously for polypyrrole (PPy) and PEDOT doped with sulphate, pTs, poly(styrenesulfonate) (PSS) and dodecylbenzenesulfonate (DBSA) [12, 13]. Uncoated platinum electrodes were bright silver while PEDOT-pTs and PEDOT-DS were dark blue (figure 1). In agreement with previous results, $45 \mathrm{~s}$ deposition of PEDOT-pTs uniformly coated the electrode surface. Deposition of PEDOT-DS generated a rougher surface coating similar to PEDOTPSS and PEDOT-DBSA [12]. Close inspection of the coating edges displayed a finer polymer structure than the PEDOT-PSS and PEDOT-DBSA coatings. The optical area of the electrode had a strong correlation with deposition time (figure 2a). Several of the coatings deposited for $60 \mathrm{~s}$ touched the edge of the shank, but only the 2 that were at the tip of the shank displayed an optical area smaller than expected. A $45 \mathrm{~s}$ deposition of PEDOT-DS produced significantly larger and rougher electrodes than 45 s deposition of PEDOT-pTs (table 1).

The total deposition charge also increased with time of conducting polymer growth (figure $2 b$ ). Unlike the deposition of PEDOT-PSS and PEDOT-DBSA, no high outliers were observed. These outliers were due to growth of the conducting polymer to the shank edge and expansion of the diffusion field of EDOT monomer to the electrode surface. $45 \mathrm{~s}$ deposition of PEDOT-DS had a significantly larger deposition charge than PEDOT-pTs, but was similar to PEDOT-PSS and PEDOT-DBSA (figure 2b) [12]. The variation in electrode area and growth rate with different dopant ions has been attributed to polymer templating [14].

A correlation of polymer deposition charge and optical area was seen (figure 3). Only the 2 PEDOTDS depositions for $60 \mathrm{~s}$ at the shank tips displayed significantly lower area than expected. The conducting polymer on these electrodes was able grow down the side of the shank so that the 2 dimensional optically measured area was undervalued.

Cyclic voltammetry of the modified electrodes was performed in $0.3 \mathrm{M}$ phosphate buffer with a potential window from $0.8 \mathrm{~V}$ to $-0.8 \mathrm{~V}$ (figure 4 ). In agreement with previous results, bare platinum electrodes showed a reduction current beginning around $-0.1 \mathrm{~V}$ which extended to the solvent window at $-0.8 \mathrm{~V}$, after switching the potential direction, the current crossed over itself at -0.6 and again at $0 \mathrm{~V}$ (figure 4a) [12]. This process is attributed to the reduction of oxygen in the non-degassed solution. Voltammetry of PEDOT-pTs was also consistent with previous results [13], displaying a relatively featureless response with large capacitance (figure 4a). PEDOT-DS possessed a broad reduction process around $-0.6 \mathrm{~V}$, shifting towards $-0.54 \mathrm{~V}$ on thicker films and small, broad oxidation processes around $-0.5 \mathrm{~V}$ and $-0.25 \mathrm{~V}$ (figure $4 \mathrm{~b}$ ). The double layer capacitance was larger than PEDOT-pTs but smaller than PEDOT-PSS [12], around $50 \mathrm{nA}$ on the thickest film, and the potential window on the oxidation scan shifted to less positive values as the film thickness increased. 
Integration of the voltammogram provides the total charge passed during the potential sweep [15]. The reductive sweep was used as many of the oxidative sweeps passed little or no charge over the potential window tested [13]. A plot of the reduction charge versus deposition time revealed 2 groups (figure $5 a)$. The smaller group (less than $-1 \mu \mathrm{C}$ ) has a strong correlation of increased reduction charge with deposition time and is associated with the electrode coatings confined to the top of the shank; the electrode coatings that touch the shank edge displayed larger reduction charges that were more variable. Plotting the reduction charge against the deposition charge produced a strong linear correlation for all coatings confined to the top of the shank (figure 5b). Electrode coatings that touched the edge of the shank were high outliers.

The electroactive area can be measured by the reduction of a solution phase redox active species such as $\mathrm{Ru}\left(\mathrm{NH}_{3}\right)_{6}{ }^{3+}[12]$. The one electron reduction

$$
\mathrm{Ru}\left(\mathrm{NH}_{3}\right)_{6}^{3+}+e^{-} \square \quad \mathrm{Ru}\left(\mathrm{NH}_{3}\right)_{6}{ }^{2+}
$$

at fast scan rates, generates a peak shaped voltammetric response with a peak current according to

$$
i_{\mathrm{p}}=\left(2.69 \times 10^{5}\right) n^{3 / 2} A D^{1 / 2} C v^{1 / 2}
$$

where $n$ is the number of electrons transferred, $D$ is the diffusion coefficient $\left(9.0 \times 10^{-6} \mathrm{~cm}^{2} \mathrm{~s}^{-1}\right), C$ is the concentration and $v$ is the scan rate. At fast scan rates (short measurement times), the $\left.\mathrm{Ru}_{(\mathrm{NH}}\right)_{6}{ }^{3+}$ diffusion profile towards the electrode surface is linear. This linear electroactive area measures all of the conductive regions that are accessible to $\mathrm{Ru}\left(\mathrm{NH}_{3}\right)_{6}{ }^{3+}$. At slow scan rates (long measurement times), $\mathrm{Ru}\left(\mathrm{NH}_{3}\right)_{6}{ }^{3+}$ must diffuse towards the electrode surface from the bulk of the solution. At small electrodes or sufficiently long measurement times, a sigmoidal shaped response is seen, and at a disc electrode the steady-state current $\left(i_{\mathrm{ss}}\right)$ has the form

$$
i_{\mathrm{ss}}=4 n F D C r
$$

where $F$ is the Faraday constant and $r$ is the electrode radius.

At a slow scan rate of $20 \mathrm{mV} \mathrm{s}^{-1}$, the reduction of $\mathrm{Ru}\left(\mathrm{NH}_{3}\right)_{6}{ }^{3+}$ at an uncoated electrode showed a sigmoidal response (figure 6a). Background subtraction of the $\mathrm{Ru}\left(\mathrm{NH}_{3}\right)_{6}{ }^{3+}$ voltammetry was used for all electroactive area measurements. A steady-state current of approximately $10 \mathrm{nA}$ is seen with a midpoint potential of $-0.24 \mathrm{~V}$. An average steady-state electroactive area of $95 \mu \mathrm{m}^{2}$ was found (table 1), in good agreement with previous values [12]. PEDOT-pTs displayed a similar response with a typical steady-state current of $17 \mathrm{nA}$ (figure 6a), and an average steady-state electroactive area of $372 \mu \mathrm{m}^{2}$ (table 1). None of the PEDOT-DS modified electrodes displayed a steady-state response with scan rates of 10 or $20 \mathrm{mV} \mathrm{s}^{-1}$ (figure $6 \mathrm{~b}$ ). On the reductive scan, a small peak was always present, and on switching the scan direction, the current crossed over itself, forming a larger reductive peak before approaching 0 $\mathrm{nA}$. The lack of a steady-state response indicates the electrodes were very large and slower scan rates 
(longer times) would be required to achieve a steady-state response. This is consistent with most of the large PEDOT-PSS modified electrodes also not achieving a steady-state response at similar voltammetric scan rates [12].

The voltammetry of $\mathrm{Ru}\left(\mathrm{NH}_{3}\right)_{6}{ }^{3+}$ at a scan rate of $200 \mathrm{mV} \mathrm{s}^{-1}$ produced peak shapes on all electrodes (figure 7). Uncoated electrodes had a reduction peak ( $\left.E_{\mathrm{p}}^{\mathrm{red}}\right)$ at $-0.3 \mathrm{~V}$ and an oxidation peak $\left(E_{\mathrm{p}}^{\mathrm{ox}}\right)$ at $-0.18 \mathrm{~V}$, giving a peak splitting $\left(\Delta E_{\mathrm{p}}=E_{\mathrm{p}}^{\mathrm{red}}-E_{\mathrm{p}}^{\mathrm{ox}}\right)$ of $120 \mathrm{mV}$ and a mid-point potential $\left.E_{1 / 2}=E_{\mathrm{p}}^{\text {red }}+E_{\mathrm{p}}^{\mathrm{ox}} / 2\right)$ of $-0.24 \mathrm{~V}$. A scan rate of $1 \mathrm{~V} \mathrm{~s}^{-1}$ reduced $\Delta E_{\mathrm{p}}$ to $85 \mathrm{mV}$, greater than the expected $60 \mathrm{mV}$, indicating the diffusion profile is not completely linear. However, use of scan rates above $1 \mathrm{~V} \mathrm{~s}^{-1}$ could not be performed on most electrodes as the background capacitance became too large, obscuring the current associated with the reduction of $\mathrm{Ru}\left(\mathrm{NH}_{3}\right)_{6}{ }^{3+}$. Calculation of the linear electroactive area according to equation 1 is therefore not strictly correct on some electrodes; however it does provide a close approximation and can be used to compare different electrodes when tested in the same manner. A typical uncoated electrode had a reduction peak current $\left(i_{\mathrm{p}}^{\text {red }}\right)$ of $9.7 \mathrm{nA}$, the average linear electroactive area was $13.2 \mu \mathrm{m}^{2}$. PEDOT-pTs had $E_{\mathrm{p}}^{\mathrm{red}}$ of $-0.285 \mathrm{~V}, E_{\mathrm{p}}^{\mathrm{ox}}=-0.18 \mathrm{~V}$, giving a $\Delta E_{\mathrm{p}}=105 \mathrm{mV}$ which decreased to $80 \mathrm{mV}$ when tested at a scan rate of $1 \mathrm{~V} \mathrm{~s}^{-1}$. A typical $i_{\mathrm{p}}^{\text {red }}$ $=23.6 \mathrm{nA}$ was found with an average linear electroactive area of $33.7 \mu \mathrm{m}^{2}$. PEDOT-DS showed peaked potentials changing with increased deposition time with typical $E_{\mathrm{p}}^{\mathrm{red}}=-0.295$ to $-0.305 \mathrm{~V}$ and $E_{\mathrm{p}}^{\mathrm{ox}}$ from -0.222 to $-0.258 \mathrm{~V}$, giving $\Delta E_{\mathrm{p}}$ close to $60 \mathrm{mV}$ on all electrodes. $i_{\mathrm{p}}^{\text {red }}$ increased with deposition time with typical values from 44 to $148 \mathrm{nA}$, giving average linear electroactive areas of 98.8, 177.9, 253.6 and $437.9 \mu \mathrm{m}^{2}$ (table 1$)$.

The linear electroactive areas could be plotted against the polymer deposition times, displaying a good correlation (figure 8). At $45 \mathrm{~s}$ deposition times, PEDOT-DS had a significantly larger electroactive area than PEDOT-pTs. The average values for linear electroactive area also show an increase in effective area with deposition time (table 1). Comparison of linear electroactive area with optically measured area also displayed a good correlation for PEDOT-DS (figure 9).

The charge density $\left(\mathrm{mC} \mathrm{cm}^{-2}\right)$ could then be measured from the reduction current and either the optical or linear electroactive area. A plot of optical and linear charge density showed a correlation across all PEDOT-DS modified electrodes, but not in line with the uncoated and PEDOT-pTs modified electrodes which is in contrast to the results seen with PEDOT-DBSA modified electrodes (figure 10) [12]. Average linear charge densities increase with deposition times, but the optical charge density was more 
variable with a larger coefficient of variation (table 2). And while the PEDOT-DS average optical charge density was larger than PEDOT-pTs and uncoated electrodes, the average linear charge densities were smaller.

\section{Discussion}

Deposition of PEDOT-DS significantly increased the electrode area, and with a $45 \mathrm{~s}$ deposition time, produced optical areas far greater than PEDOT-pTs and slightly larger than PEDOT-DBSA and PEDOT-PSS [12]. The trend in increased electrode optical area is in line with the increasing molecular weight of each dopant ion, pTs $<$ DBSA $<$ PSS $($ MW $=70,000)<$ DS $($ MW $>500,000)$. It has been reported that the change in dopant ion has minimal effect on the solution viscosity, and that variations in electrode size are due to the dopant templating the conducting polymer growth [14]. In this process, the larger dopant ions can direct growth of the PEDOT polymer chains away from the electrode surface towards the bulk solution. This may reduce any blocking of the growing polymer by other polymer chains. During polymer growth, EDOT is reduced at the electrode surface, lowering its local concentration, which requires diffusion of more monomer to the electrode surface for further polymerisation. Therefore, growth of the conducting polymer into the bulk solution will also reduce the distance from the growing electrode surface to other EDOT monomers. This allows the polymer to grow more rapidly, as demonstrated by the larger deposition charges measured for equivalent times of PEDOT-DS vs PEDOT-pTs (figure 2b).

A variation in conducting polymer morphology was seen with increased dopant size, the small pTs producing reproducible disc geometries; DBSA and PSS displayed rough, nodular structures with growth fronts directed along the electrode tracks embedded in the shank; DS also produced a rough surface but with a finer structure. This change in conducting polymer morphology can be expected, as deposition of the charged polymer must incorporate a dopant ion to maintain charge neutrality, larger dopant ions require more room, and therefore greater spacing between polymer chains. The large size of the DS dopant ion would make it difficult to eject from the deposited polymer, ensuring the electrode functionality is maintained when implanted into the body. This type of polymer structure would also ensure that some of the DS dopant ion is exposed to the surrounding solution, and may be of benefit as an antithrombotic, leading to improved biocompatibility of an electrode modified with this material.

The voltammetry of PEDOT-DS displays a large background capacitance with a small non-reversible Faradaic reaction around $-0.5 \mathrm{~V}$, similar to drop cast films [16]. This demonstrates the highly conductive nature and large reductive charge available from this electrode coating. These properties are required for the electrical stimulation of cells. By generating sufficient charge to stimulate a cell from a smaller electrode area, this material also allows the electrode size to be reduced. The foreign body response is also affected by the size of an implanted device [17]. Therefore, as well as the 
antithrombotic benefits of DS, microelectrodes coated with PEDOT-DS may be able to stimulate individual cells and reduce the immune response to the foreign body.

The electroactive area of different electrode materials gives further information on their roughness and chemical structure. To achieve a steady-state response for the reduction of $\mathrm{Ru}\left(\mathrm{NH}_{3}\right)_{6}{ }^{3+}$ the electrode size must be small enough to enable a convergent diffusion profile. A steady-state response was found on uncoated and PEDOT-DBSA modified Pt microelectrodes but not PEDOT-PSS or PEDOT-DS modified electrodes [12]. This is consistent with the optical area of PEDOT-PSS and PEDOT-DS being significantly larger than PEDOT-pTs. In contrast, at fast scan rates, all of these electrodes have displayed peaked, reversible voltammetry with close to ideal linear diffusion behaviour. The ratio of linear electroactive area to optical area was similar between PEDOT-DS and PEDOT-PSS, but larger than PEDOT-DBSA, PEDOT-pTs and bare platinum. This indicates a greater portion of the electrode surface on these two materials is electrochemically functional. PEDOT-DBSA and PEDOT-DS had strong correlations between linear electroactive area, optical area and deposition time. However PEDOT-PSS didn't show correlations between these parameters. This difference with PEDOT-PSS is due to greater coefficient of variation in the linear area values and most likely attributed to the large background capacitance and error in background subtraction.

There was a correlation between the linear and optical charge density of PEDOT-DS modified microelectrodes. Once again this is similar to PEDOT-DBSA, while PEDOT-PSS showed no correlation. The ratio of linear charge density to optical charge density for PEDOT-DS was different to all the other electrode materials, so while the relative electrochemically active electrode area is large, the relative charge that is delivered from the electrode is lower than the other materials.

\section{Conclusions}

Electropolymerisation of PEDOT-DS increases the electrode area, creating a rough morphology similar to other doped conducting polymers. The electrode geometric area is well correlated with deposition time and charge. Voltammetry of PEDOT-DS in a phosphate solution displayed a large background capacitance with small Faradaic processes. The reduction charge was strongly correlated to deposition time and charge, and significantly larger than unmodified or PEDOT-pTs modified electrodes. Reduction of $\mathrm{Ru}\left(\mathrm{NH}_{3}\right)_{6}{ }^{3+}$ at fast scan rates allowed measurement of a linear electroactive area which strongly correlated to deposition time and geometric area. The electrodes were too large to achieve a steady-state reduction of $\mathrm{Ru}\left(\mathrm{NH}_{3}\right)_{6}{ }^{3+}$ down to voltammetric scan rates $10 \mathrm{mV} \mathrm{s}^{-1}$. There was a good correlation between optical and linear charge densities. The coefficient of variation between optical and linear electroactive areas was similar, but the optical charge density was significantly greater than the linear charge density. 


\section{Acknowledgements}

The authors acknowledge the support of the Australian Research Council through the Centre of Excellence for Electromaterials Science. 


\section{References}

[1] G.C. McConnell, et al., Implanted neural electrodes cause chronic, local inflammation that is correlated with local neurodegeneration, Journal of Neural Engineering, 6 (2009) 056003.

[2] P.J. Rousche, R.A. Normann, Chronic recording capability of the Utah Intracortical Electrode Array in cat sensory cortex, Journal of Neuroscience Methods, 82 (1998) 1-15.

[3] W. Grill, J. Thomas Mortimer, Electrical properties of implant encapsulation tissue, Annals of Biomedical Engineering, 22 (1994) 23-33.

[4] X. Cui, J.F. Hetke, J.A. Wiler, D.J. Anderson, D.C. Martin, Electrochemical deposition and characterization of conducting polymer polypyrrole/PSS on multichannel neural probes, Sensors and Actuators A: Physical, 93 (2001) 8-18.

[5] P.M. George, A.W. Lyckman, D.A. LaVan, A. Hegde, Y. Leung, R. Avasare, C. Testa, P.M. Alexander, R. Langer, M. Sur, Fabrication and biocompatibility of polypyrrole implants suitable for neural prosthetics, Biomaterials, 26 (2005) 3511-3519.

[6] K.A. Ludwig, J.D. Uram, J. Yang, D.C. Martin, D.R. Kipke, Chronic neural recordings using silicon microelectrode arrays electrochemically deposited with a poly(3,4-ethylenedioxythiophene) (PEDOT) film, Journal of Neural Engineering, 3 (2006) 59.

[7] B.C. Thompson, S.E. Moulton, R.T. Richardson, G.G. Wallace, Effect of the dopant anion in polypyrrole on nerve growth and release of a neurotrophic protein, Biomaterials, 32 (2011) 38223831.

[8] J.N. Barisci, R. Stella, G.M. Spinks, G.G. Wallace, Characterisation of the topography and surface potential of electrodeposited conducting polymer films using atomic force and electric force microscopies, Electrochimica Acta, 46 (2000) 519-531.

[9] A. Gelmi, M.J. Higgins, G.G. Wallace, Resolving Sub-Molecular Binding and Electrical Switching Mechanisms of Single Proteins at Electroactive Conducting Polymers, Small, 9 (2013) 393-401.

[10] A. Gelmi, M.K. Ljunggren, M. Rafat, E.W.H. Jager, Influence of conductive polymer doping on the viability of cardiac progenitor cells, Journal of Materials Chemistry B, 2 (2014) 3860-3867.

[11] S.B. Brummer, M.J. Turner, Electrical Stimulation with Pt Electrodes: A Method for Determination of "Real" Electrode Areas, Biomedical Engineering, IEEE Transactions on, BME-24 (1977) 436-439.

[12] A.R. Harris, P.J. Molino, R.M.I. Kapsa, G.M. Clark, A.G. Paolini, G.G. Wallace, Optical and Electrochemical Methods for Determining the Effective Area and Charge Density of Conducting Polymer Modified Electrodes for Neural Stimulation, Analytical Chemistry, 87 (2015) 738-746. [13] A.R. Harris, S.J. Morgan, J. Chen, R.M.I. Kapsa, G.G. Wallace, A.G. Paolini, Conducting polymer coated neural recording electrodes, Journal of Neural Engineering, 10 (2013) 016004. [14] V. Lyutov, I. Efimov, A. Bund, V. Tsakova, Electrochemical polymerization of 3,4ethylenedioxythiophene in the presence of dodecylsulfate and polysulfonic anions-An acoustic impedance study, Electrochimica Acta, 122 (2014) 21-27.

[15] A.R. Harris, S.J. Morgan, G.G. Wallace, A.G. Paolini, A Method for Systematic Electrochemical and Electrophysiological Evaluation of Neural Recording Electrodes, Journal of Visualized Experiments, (2014) e51084.

[16] D.G. Harman, R. Gorkin Iii, L. Stevens, B. Thompson, K. Wagner, B. Weng, J.H.Y. Chung, M. in het Panhuis, G.G. Wallace, Poly(3,4-ethylenedioxythiophene):dextran sulfate (PEDOT:DS) - A highly processable conductive organic biopolymer, Acta Biomaterialia, 14 (2015) 33-42.

[17] T.D. Yoshida Kozai, N.B. Langhals, P.R. Patel, X. Deng, H. Zhang, K.L. Smith, J. Lahann, N.A. Kotov, D.R. Kipke, Ultrasmall implantable composite microelectrodes with bioactive surfaces for chronic neural interfaces, Nat Mater, advance online publication (2012). 
Table 1. Average, standard deviation and coefficient of variation of electrode area measured optically or by reduction of $\mathrm{Ru}\left(\mathrm{NH}_{3}\right)_{6}{ }^{3+}$ for a steady-state or linear electroactive area.

\begin{tabular}{lccccccccc}
\hline Polymer coating & \multicolumn{3}{c}{ Optical Area $\left(\mu \mathrm{m}^{2}\right)$} & \multicolumn{3}{c}{$\begin{array}{c}\text { Steady-state Electroactive } \\
\text { Area }\left(\mu \mathrm{m}^{2}\right)\end{array}$} & \multicolumn{3}{c}{$\begin{array}{c}\text { Linear Electroactive } \\
\text { Area }\left(\mu \mathrm{m}^{2}\right)\end{array}$} \\
\cline { 2 - 11 } & Ave & SD & CV & Ave & SD & CV & Ave & SD & CV \\
\hline 15s PEDOT-DS & 1004.9 & 92.0 & 0.09 & - & - & - & 98.8 & 11.1 & 0.11 \\
30s PEDOT-DS & 1565.6 & 128.1 & 0.08 & - & - & - & 177.9 & 37.1 & 0.21 \\
45s PEDOT-DS & 2270.5 & 200.1 & 0.09 & - & - & - & 253.6 & 41.3 & 0.16 \\
60s PEDOT-DS & 2609.5 & 452.3 & 0.17 & - & - & - & 437.9 & 150.6 & 0.34 \\
45s PEDOT-pTs & 794.4 & 105.2 & 0.13 & 372.3 & 100.8 & 0.27 & 33.7 & 4.1 & 0.12 \\
Uncoated & 420.3 & 16.1 & 0.04 & 94.6 & 19.7 & 0.21 & 13.2 & 1.2 & 0.09 \\
\hline
\end{tabular}

Table 2. Average, standard deviation and coefficient of variation of electrode charge density measured from the reduction charge and optical, steady-state or linear electroactive area.

\begin{tabular}{lccccccccc}
\hline \multirow{2}{*}{ Polymer coating } & \multicolumn{3}{c}{$\begin{array}{c}\text { Optical Charge Density } \\
\left(\mathrm{mC} / \mathrm{cm}^{2}\right)\end{array}$} & \multicolumn{3}{c}{$\begin{array}{c}\text { Steady-state Charge } \\
\text { Density }\left(\mathrm{mC} / \mathrm{cm}^{2}\right)\end{array}$} & \multicolumn{3}{c}{$\begin{array}{c}\text { Linear Charge Density } \\
\left(\mathrm{mC} / \mathrm{cm}^{2}\right)\end{array}$} \\
\cline { 2 - 11 } & Ave & SD & CV & Ave & SD & CV & Ave & SD & CV \\
\hline 15s PEDOT-DS & 42.8 & 74.3 & 1.73 & - & - & - & 167.1 & 9.7 & 0.06 \\
30s PEDOT-DS & 62.1 & 68.3 & 1.10 & - & - & - & 218.1 & 43.9 & 0.20 \\
45s PEDOT-DS & 36.0 & 26.9 & 0.75 & - & - & - & 223.1 & 12.9 & 0.06 \\
60s PEDOT-DS & 62.8 & 42.4 & 0.68 & - & - & - & 298.9 & 94.4 & 0.32 \\
45s PEDOT-pTs & 21.8 & 2.6 & 0.12 & 48.9 & 13.3 & 0.27 & 512.8 & 50.8 & 0.10 \\
Uncoated & 15.5 & 1.5 & 0.09 & 70.9 & 13.0 & 0.18 & 492.5 & 42.7 & 0.09 \\
\hline
\end{tabular}




\section{Figure Captions}

Figure 1. Optical microscopy of platinum electrodes (a) before and (b-j) after deposition of PEDOT doped with (b) pTs for $45 \mathrm{~s}$ (c-f) DS for 15, 30, 45 and $60 \mathrm{~s}$.

Figure 2. (a) Optically measured electrode area and (b) total deposition charge passed versus deposition time while depositing PEDOT doped with DS or pTs. The two shank tip electrodes modified with a 60 $\mathrm{s}$ deposition of PEDOT-DS have been labelled.

Figure 3. Optically measured electrode area versus total charge passed during deposition of PEDOT doped with DS or pTs. The two shank tip electrodes modified with a $60 \mathrm{~s}$ deposition of PEDOT-DS have been labelled.

Figure 4. Cyclic voltammetry in $0.3 \mathrm{M} \mathrm{Na}_{2} \mathrm{HPO}_{4}$ at $100 \mathrm{mV} \mathrm{s}^{-1}$ of (a) an uncoated electrode and electrode coated with a $45 \mathrm{~s}$ deposition of PEDOT-pTs (b) PEDOT-DS at varying deposition times.

Figure 5. Charge measured from reductive scan of electrodes in $0.3 \mathrm{M} \mathrm{Na}_{2} \mathrm{HPO}_{4}$ at $100 \mathrm{mV} \mathrm{s}^{-1}$ versus (a) deposition time and (b) total charge passed during deposition of PEDOT doped with DS or pTs. Deposited conducting polymers on electrodes below the dashed lines have touched the edge or tip of the shank and are not included in determining the correlations.

Figure 6. Background subtracted cyclic voltammetry of $5 \mathrm{mM} \mathrm{Ru}\left(\mathrm{NH}_{3}\right)_{6}{ }^{3+}$ in $0.3 \mathrm{M} \mathrm{Na}_{2} \mathrm{HPO}_{4}$ at $10 \mathrm{mV}$ $\mathrm{s}^{-1}$ at (a) an uncoated electrode and electrode coated with $45 \mathrm{~s}$ deposition of PEDOT-pTs (b) PEDOTDS at varying deposition times.

Figure 7. Background subtracted cyclic voltammetry of $5 \mathrm{mM} \mathrm{Ru}\left(\mathrm{NH}_{3}\right)_{6}{ }^{3+}$ in $0.3 \mathrm{M} \mathrm{Na}_{2} \mathrm{HPO}_{4}$ at 200 $\mathrm{mV} \mathrm{s}^{-1}$ at (a) an uncoated electrode and electrode coated with $45 \mathrm{~s}$ deposition of PEDOT-pTs (b) PEDOT-DS at varying deposition times.

Figure 8. Comparison of electrochemically measured electrode area versus deposition time of PEDOT doped with DS. Linear diffusion response of $5 \mathrm{mM} \mathrm{Ru}\left(\mathrm{NH}_{3}\right)_{6}{ }^{3+}$ in $0.3 \mathrm{M} \mathrm{Na}_{2} \mathrm{HPO}_{4}$.

Figure 9. Comparison of electrochemically measured versus optically measured electrode area of PEDOT doped with DS. Linear diffusion response of $5 \mathrm{mM} \mathrm{Ru}\left(\mathrm{NH}_{3}\right)_{6}{ }^{3+}$ in $0.3 \mathrm{M} \mathrm{Na}_{2} \mathrm{HPO}_{4}$.

Figure 10. Comparison of charge density of PEDOT doped with DS with different electrode area measurements. 


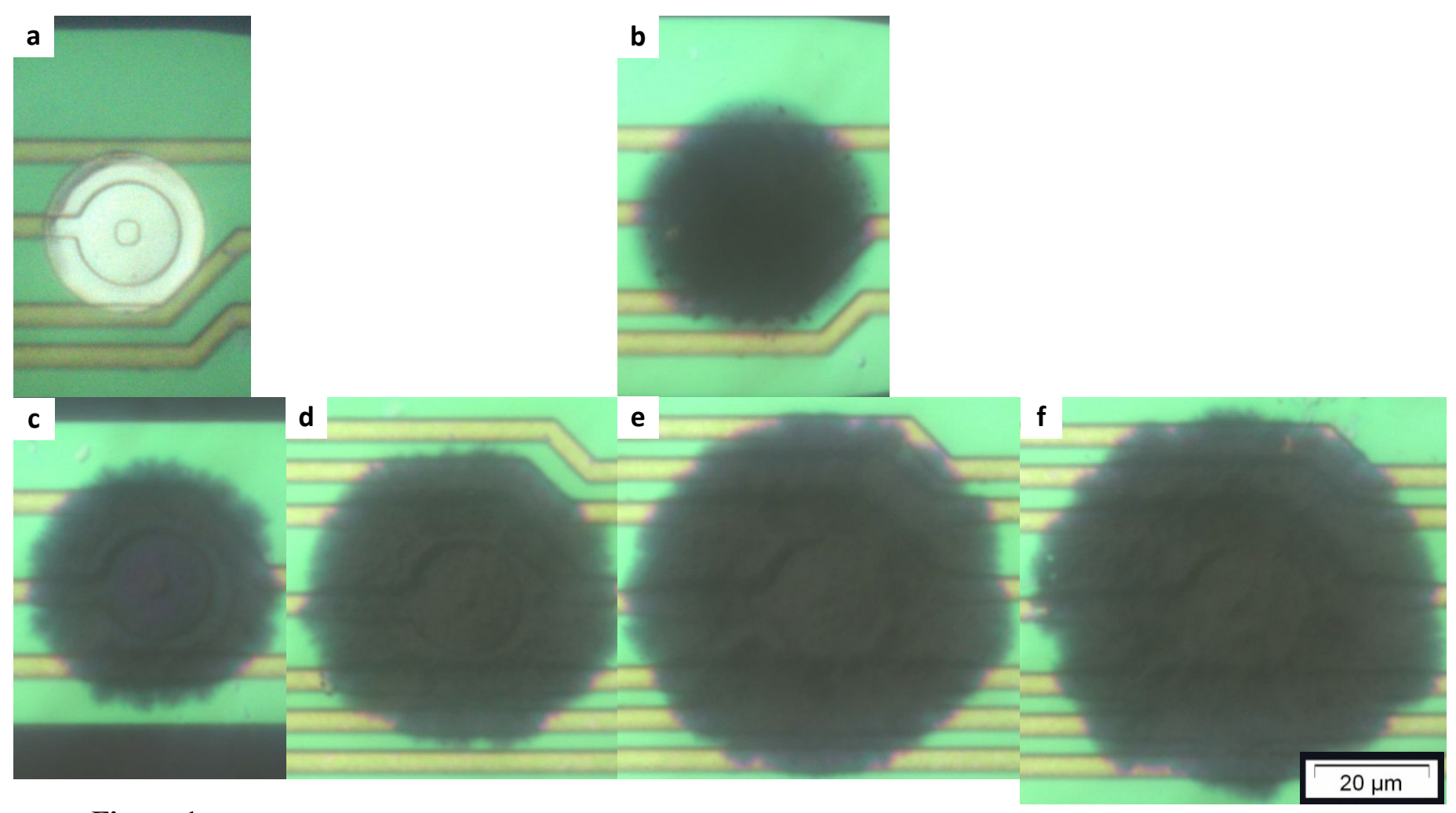

Figure 1

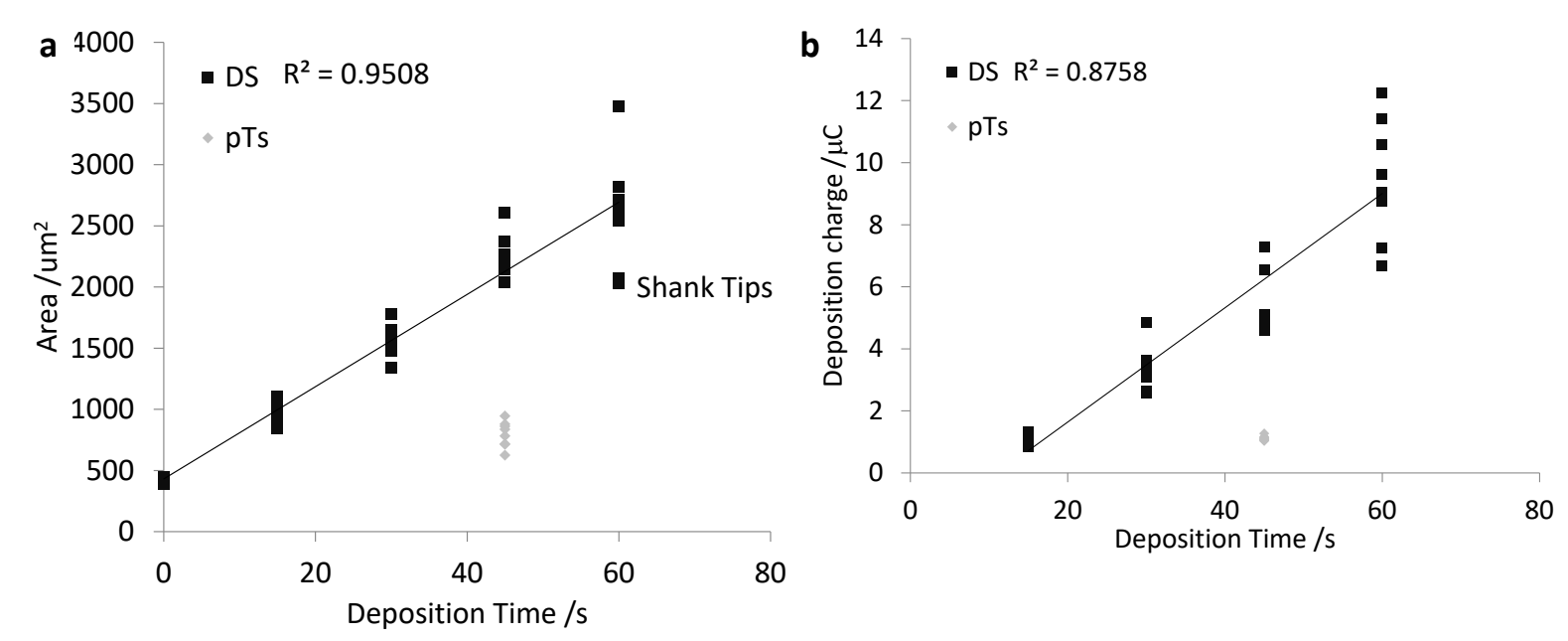

Figure 2 


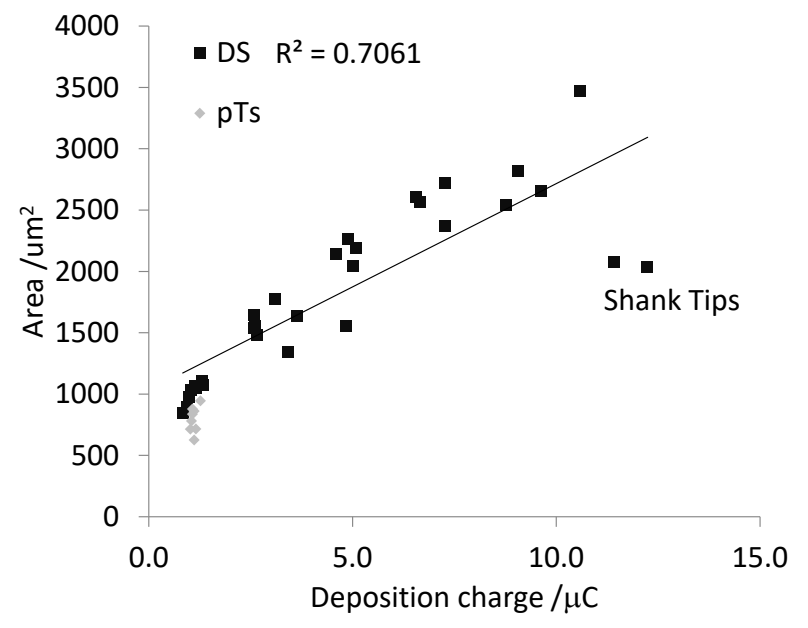

Figure 3

a

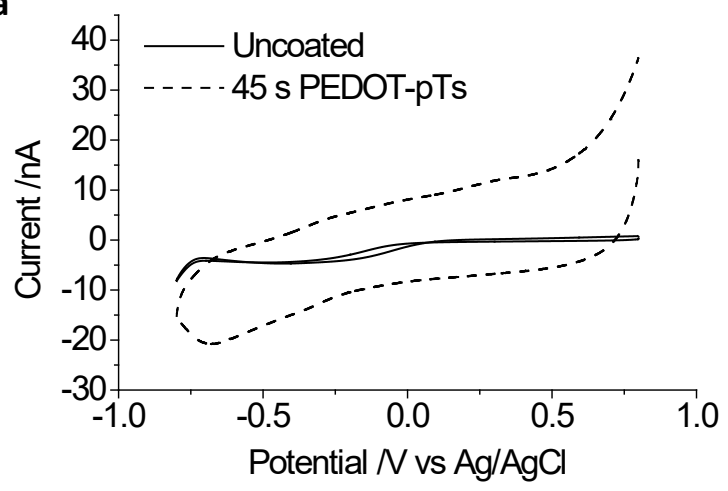

b

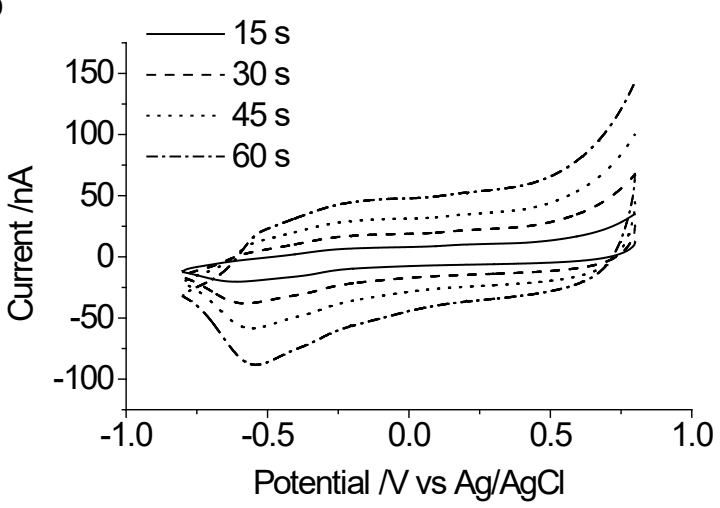

Figure 4
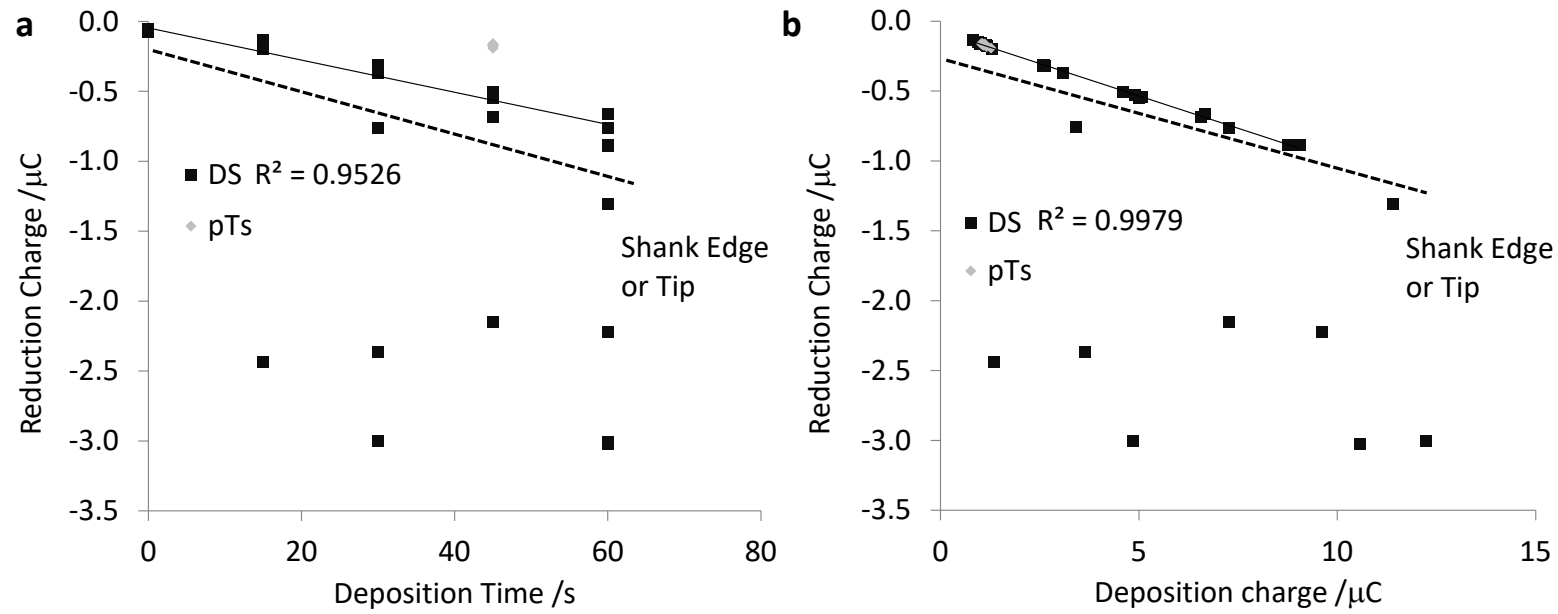

Figure 5 
a

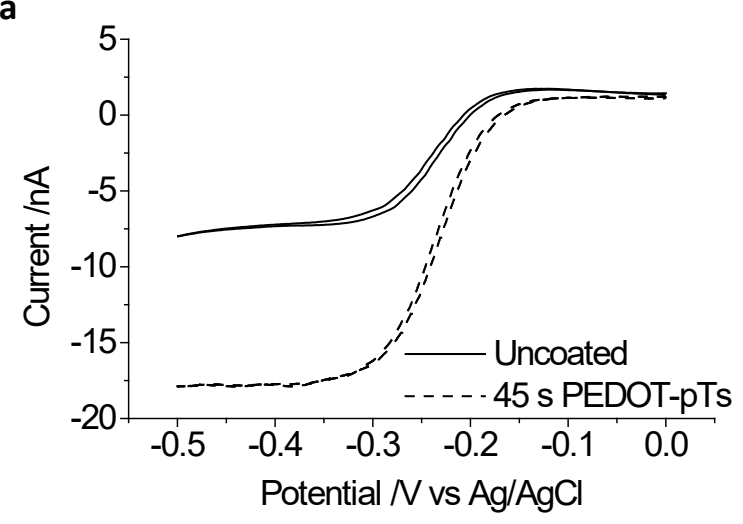

b

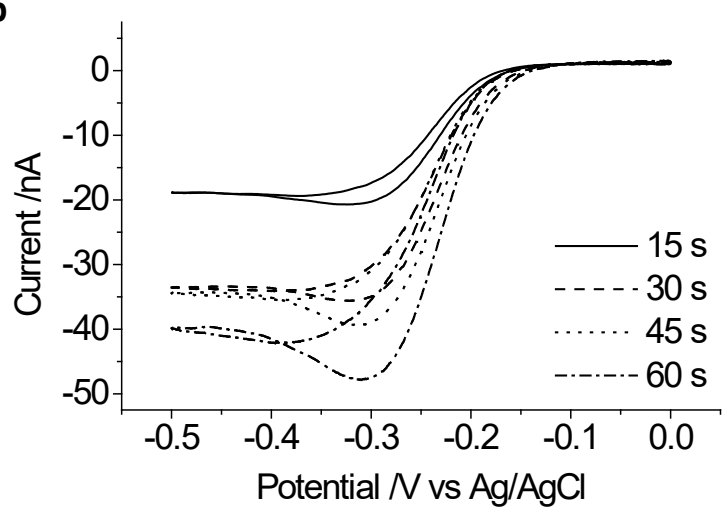

Figure 6

a

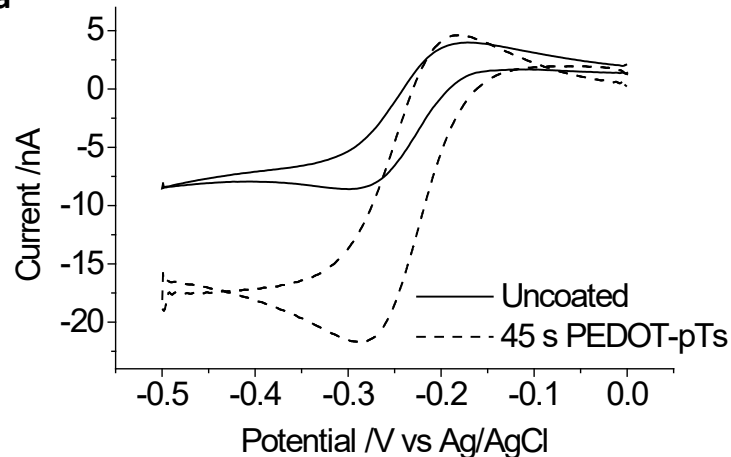

b

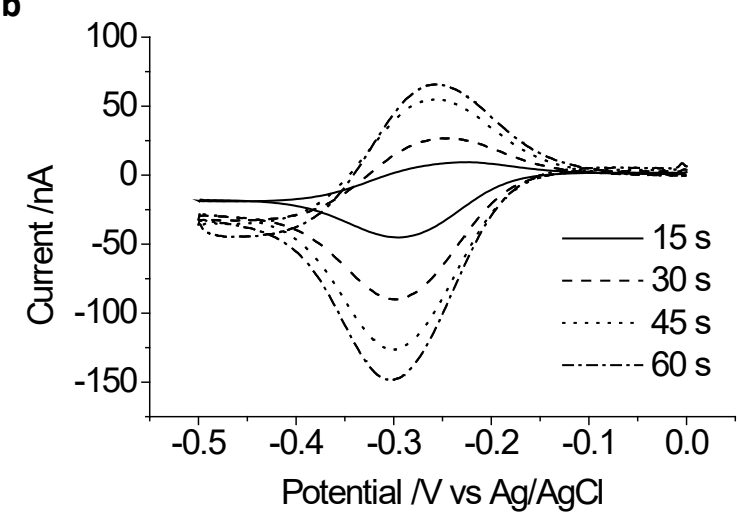

Figure 7

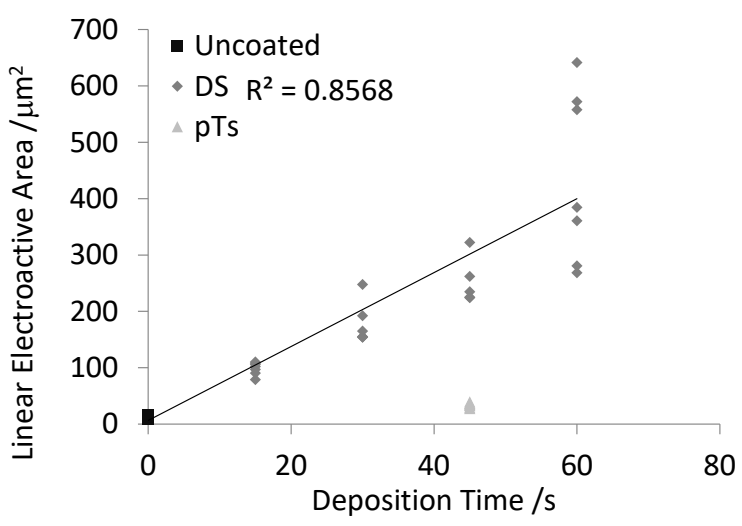

Figure 8 


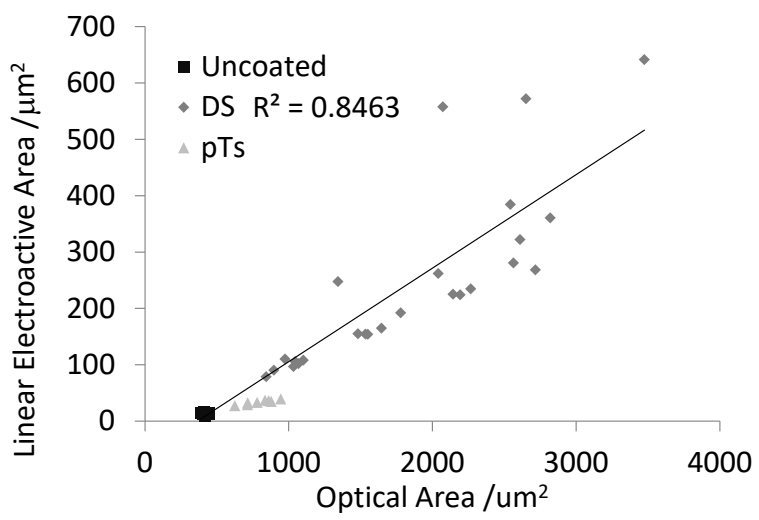

Figure 9

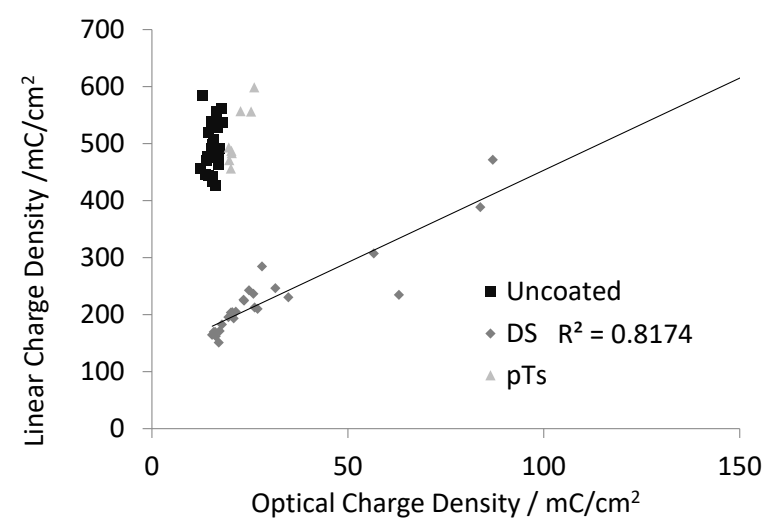

Figure 10 